\title{
Desenvolvimento lexical e gramaticalização na aquisição do português brasileiro
}

Mirian Rose Brum de Paula

Giovana Ferreira Gonçalves ${ }^{b}$

\begin{abstract}
Resumo
O presente trabalho, partindo de uma perspectiva funcionalista e emergentista para o processo de aquisição da linguagem, em que padrões gramaticais são concebidos enquanto estruturas que emergem do léxico, busca refletir acerca da maneira como ocorre a aquisição do léxico verbal e ofenômeno da gramaticalização. Os resultados obtidos apoiam o modelo from reference to predication to grammar e a hipótese da massa lexical crítica propostos por Bates et al (1994; 1997) e Bates e Goodman (1999).
\end{abstract}

Palavras chave: morfologia verbal; aquisição da linguagem; gramaticalização 


\section{Introdução}

Este artigo busca compreender como ocorrem a construção do léxico verbal e a emergência da gramática morfológica na criança pequena. Para tanto, acompanhamos o desenvolvimento de duas classes de palavras - nomes e verbos -, a progressão e a ordem de aparição dos tempos verbais durante os primeiros três anos de existência de um único informante. A pesquisa é de cunho longitudinal, reporta e examina as relações existentes entre o desenvolvimento lexical e gramatical. Os resultados obtidos são comparados com os de outros estudos, envolvendo línguas tipologicamente semelhantes, a saber: o francês e o alemão austríaco.

A concepção dinâmica adotada prevê relação mútua e de complementaridade entre os processos de aquisição do léxico e da construção da gramática. Esses diferentes componentes da linguagem estariam intimamente associados e desenvolver-se-iam em estreita relação de causa e efeito. Haveria, pois, conexão, influência e integração entre essas distintas dimensões da linguagem. $\mathrm{O}$ foco da investigação concerne, consequentemente, a análise, a articulação e a interação desses componentes (BATES et al, 1995; BASSANO, 1998).

É importante ressaltar, no entanto, a posição peculiar do léxico em relação a outros aspectos da língua (fonético-fonológicos ou sintáticos), pois a sua apropriação é constante, ocorrendo ao longo de nossas vidas, sem oferecer resistências aparentes. Em adultos, o êxito relativo à sua aquisição pode ser ilustrado com a aprendizagem de línguas estrangeiras. Nessa situação, somos capazes de acumular vocabulário sem que isso seja percebido como uma árdua tarefa. Combinar elementos e produzir sons estrangeiros, no entanto, podem demandar mais esforço e talento, o que, evidentemente, não significa dissociação entre fonética, fonologia, sintaxe, morfologia ou pragmática, por exemplo. Evidentemente, embora dê essa impressão, a tarefa não é pouco onerosa e, tampouco, idêntica em todas as fases de nossa existência. Ao contrário, o processamento dos diferentes tipos de léxico que formam o sistema linguístico ao qual estamos expostos e que, diariamente, empregamos, é complexo e ocorre de modo irregular. A não linearidade do seu desenvolvimento, porém, é um padrão esperado dos sistemas emergentes. Com efeito, crianças não adquirem as diferentes categorias lexicais - 
ou uma mesma categoria - de modo homogêneo e linear. Embora não seja uma característica universal, o ritmo de desenvolvimento lexical infantil tende, tipicamente, a sofrer altos e baixos intercalando momentos de progressão lenta com períodos de aceleração brusca. Aspectos de cunho tanto quantitativos como qualitativos estão envolvidos nesse processo.

\section{Nomes e verbos}

Dependendo das características do elemento linguístico a ser aprendido e produzido pela criança, pode haver uma maior ou menor facilidade - e precocidade - em relação a sua aquisição. As pesquisas sobre o desenvolvimento de nomes e verbos em crianças expostas a línguas europeias parecem confirmar a intuição popular e as observações parentais de que nomes seriam quantitativamente mais empregados do que verbos na aquisição inicial da linguagem.

Gentner (1976), após reportar resultados de pesquisa encontrados na literatura acerca da aquisição de verbos e nomes e, igualmente, resultados obtidos por meio de suas próprias investigações, confirma a predominância de nomes simples - próprios e concretos - em relação a verbos, na aquisição precoce da língua inglesa. Para a autora, as diferenças entre o significado relacional expresso pelos verbos e o significado referencial expresso pelos nomes explicariam a aprendizagem mais rápida dessa última categoria e o lento desenvolvimento da primeira.

Boysson-Bardies (2005) observa variações importantes nas proporções de nomes, verbos e palavras sociais na composição do vocabulário infantil, mas, de modo geral, também destaca o número pouco elevado de verbos no primeiro repertório lexical da criança. Segundo essa estudiosa, o sentido do verbo seria mais difícil de ser compreendido pela criança. Nomes, no entanto, seriam mais facilmente identificados no mundo concreto. Além disso, Boysson-Bardies concorda com Gleitman (1990) no que diz respeito a uma provável dependência do desenvolvimento dos verbos em relação à sintaxe. A estrutura sintática restringiria o sentido dos verbos orientando sua interpretação. A compreensão dos enunciados facilitaria, assim, a aprendizagem dos verbos. 
Bassano (2005, 2010) e Bassano et al (2001) , investigando a aquisição dos verbos em crianças de língua francesa e alemã, destaca a predominância dos nomes - em relação a verbos - na elaboração do vocabulário inicial da criança, pelo menos no que diz respeito a ocorrências (tokens). Para tentar dar conta do descompasso existente entre essas duas categorias, a pesquisadora lança mão de explicações diversas, a saber: (i) a maior complexidade cognitiva e gramatical dos verbos, (ii) o fato de os verbos, frequentemente, não corresponderem a experiências presentes, (iii) e, enfim, a frequência, a posição e a saliência pragmática dos verbos no input linguístico.

Quintero e Pérez (2007), estudando a proporção de verbos e substantivos na fala infantil e nas produções de seus cuidadores, obtiveram, na aquisição do espanhol como língua materna, resultados convergentes com os de outros trabalhos que reportam o predomínio de substantivos sobre os verbos nas primeiras etapas do desenvolvimento lexical da criança.

\section{Léxico e gramática}

Quanto à relação entre o léxico e a gramática, Bates e Goodman (1999) destacam a necessidade de que um estoque lexical básico seja constituído e esteja disponível para a criança a fim de que a aquisição gramatical possa se realizar. A assincronia temporal observada entre a emergência do léxico e a aparição da gramática revelaria uma poderosa relação de causa e efeito e de interdependência entre esses dois elementos. Não haveria dissociação entre o léxico e a gramática no desenvolvimento da linguagem. Pelo contrário, tal relação revelaria que o léxico e a gramática estariam sendo mediados pelos mesmos mecanismos mentais e neuroniais.

$\mathrm{Na}$ fórmula "from reference to predication to grammar", enunciada por Bates et al (1994), que sintetiza as principais tendências desenvolvimentais concernentes à produção lexical, a assincronia temporal existente entre a aquisição de nomes, verbos e o processo de gramaticalização indicaria forte conexão, interdependência e relação causal entre esses componentes. Além disso, a passagem de um estágio a outro pressuporia a presença de zonas de aceleramento - ou explosões - no ritmo de desenvolvimento da linguagem. Assim, a emergência da 
categoria dos nomes (referência) precederia o desenvolvimento dos verbos (predicação) e, ambos, nomes e verbos combinados, promoveriam a gramaticalização. Segundo Bates et al (1994), a criança necessitaria de uma certa massa lexical, ou seja, de uma certa quantidade de itens lexicais para atingir estágios qualitativos mais avançados relativos à predicação e à gramaticalização.

Influenciada pela ideia - presente nos trabalhos de Bates, Dale e Thal (1997) e Bates e Goodman (1999) - de que o desenvolvimento gramatical inicial dependeria do desenvolvimento lexical ou, em outras palavras, de uma determinada massa lexical crítica, Bassano $(2005,2010)$ emitiu a hipótese do princípio léxico-semântico da gramaticalização. A autora sugere que a gramaticalização poderia estar relacionada tanto ao tamanho (massa lexical crítica) quanto à estrutura e à natureza do léxico presentes na fala infantil.

\section{Metodologia}

O corpus utilizado integra o banco de dados LIDES (Linguagem Infantil em Desenvolvimento), organizado por pesquisadores da Universidade Federal de Pelotas (UFPel) e da Universidade Católica de Pelotas, localizadas no extremo sul do Brasil. Tal banco faz parte do acervo de dados orais do Laboratório Emergência da Linguagem Oral (LELO) da UFPel. As coletas foram realizadas pelos cuidadores dos bebês em ambiente familiar. As situações são naturais e variadas, incluindo sequências de jogos e rotinas cotidianas. Trata-se de um corpus longitudinal contendo gravações mensais que correspondem, cada uma, a trinta minutos de fala, aproximadamente. Dentre as produções das oito crianças que compõem o banco LIDES, reportamos, neste artigo, o trabalho realizado com os dados de SM, filho único de um casal de classe média da cidade de Santa Maria, cidade central do Rio Grande do Sul.

As produções de $\mathrm{SM}$, bem como as de seus cuidadores, foram transcritas e, posteriormente, submetidas a um levantamento de percentuais de frequência pelo programa computacional Word Smith Tools. Dentre os aspectos analisados destacamos (i) os tipos (types) e as ocorrências (tokens) de nomes e verbos produzidos em cada coleta e (ii) a ordem de aparição e as tendências desenvolvimentais dos tempos verbais. 
A exemplo de Bassano (2001; 2010), utilizamos dois índices qualitativos para definir a emergência das formas verbais empregadas pelo informante: um índice de emergência (IE) e um índice que aponta o início da aquisição (IA). O primeiro corresponde ao momento em que a forma aparece nos dados de SM e o segundo ao momento em que ela é empregada de modo produtivo. A produtividade é avaliada segundo dois critérios: 0 critério fraco indica que a mesma forma é empregada com pelo menos dois lemmas distintos (ele faz e ele come, por exemplo); o critério forte indica que um mesmo lemma verbal aparece, nos dados da criança, sob duas formas diferentes (sou e é ou come e comeu). Ainda, para estabelecer o índice de gramaticalização dos verbos, empregamos as formas compostas empregadas por SM. Para tanto, calculamos a relação das formas compostas utilizadas sobre o número total de infinitivos, gerúndios e particípios passados constantes nas sete coletas analisadas. Tais coletas compreendem o período de vinte e dois a trinta e seis meses de vida do informante (de 01:10 a 03:00). Como é possível observar nos gráficos relacionados nos itens seguintes, essas amostras incluem as produções realizadas quando o bebê tinha 01:10, 01:11, 02:04, 02:05, 02:09, 02:11 e 03:00 (idades dispostas no eixo horizontal dos gráficos).

SM tinha vinte e dois meses quando ocorreu a primeira gravação. Nela, empregou diversos tipos de palavras, além de outros sons de interpretação duvidosa. Nessa amostra, utilizou nove substantivos e três verbos diferentes. Na última coleta selecionada, SM tinha trinta e seis meses e fez uso de 107 substantivos e 43 verbos distintos. Pouco mais de um ano separam essas duas amostras tão desiguais. Como explicar o salto quantitativo - e qualitativo - operado ao longo dos 14 meses que as separam? De que modo ocorre essa aquisição?

No próximo item, tentaremos contribuir com alguns elementos de reposta a essas questões. Para fazê-lo, reportamos os diferentes tipos e ocorrências de nomes e verbos constantes nas sete amostras trabalhadas, identificamos a ordem em que os tempos verbais emergem, as tendências desenvolvimentais dos tempos verbais mais empregados e comparamos esses resultados com os obtidos em outros trabalhos acerca da aquisição da linguagem expressiva. 


\section{Tipos e ocorrências de nomes e verbos}

No que concerne à frequência por tipos (types), em termos percentuais, a produção de nomes diferentes é sempre superior ao uso de verbos diferentes nos dados de SM. Como é possível observar na Figura 1, essa predominância ocorre em todas as sete amostras de fala analisadas.

Figura 1 - Percentuais de verbos e nomes (tipos)

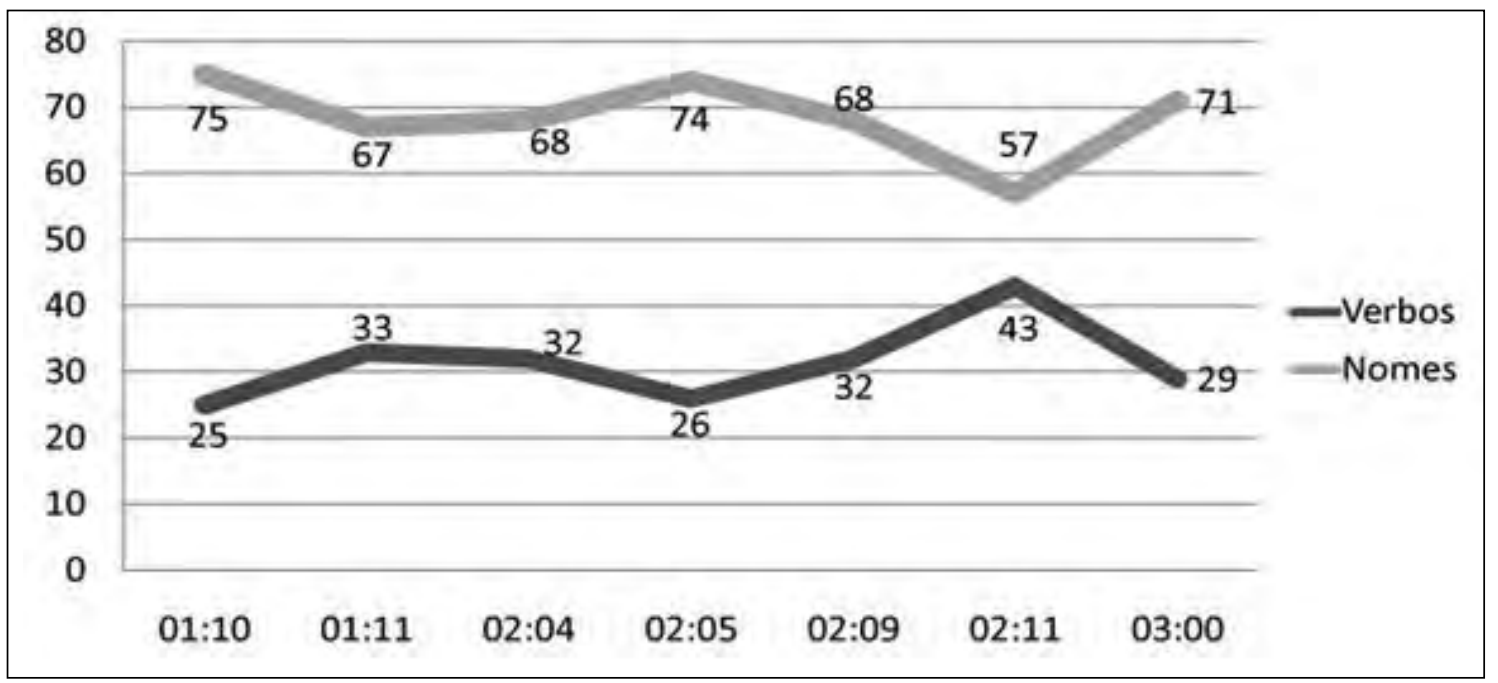

No entanto, essa configuração muda quando observamos a frequência total de ocorrências (tokens) de nomes e verbos empregados. Na Figura 2, verificamos que os percentuais de nomes tendem a diminuir ao longo do tempo e os relativos aos verbos a aumentar. Assim, o percentual de nomes é nitidamente superior em frequência entre 1:10 e 1:11. Essa diferença inicial diminui entre 2:04 e 2:05. Quando SM está com 2:09, o emprego das duas categorias é praticamente equivalente, pois $52 \%$ são nomes e $48 \%$ verbos. Em 2:11, ocorre, então, uma inversão relativa à freqüência de ambas. Assim, em termos de ocorrência, os verbos passam a ser mais empregados do que nomes a partir desse momento. Essa tendência permanece nos dados da última coleta. 
Figura 2 - Percentuais de verbos e nomes (ocorrências)

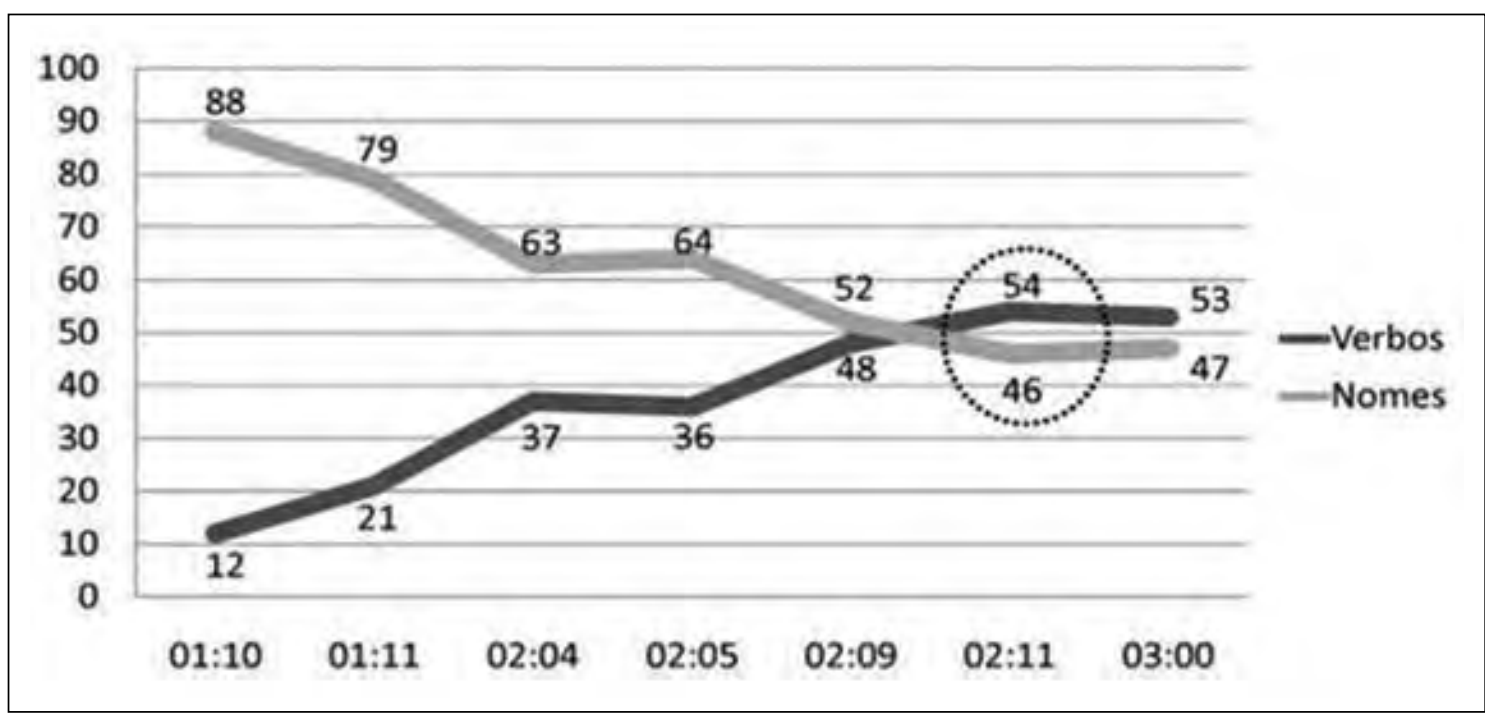

Bassano (2010) identificou essa inversão na hierarquia de freqüência em seus trabalhos acerca da aquisição do francês como língua materna. Os dados longitudinais que analisou eram constituídos de produções da pequena Pauline, quando esta tinha entre 01:02 e 03:00. Além dos dados dessa informante, a pesquisadora utilizou, para fins de comparação e generalização das tendências observadas, dados complementares de outras 80 crianças acompanhadas transversalmente. Segundo a pesquisadora, em termos de tipos, para todos os informantes, o uso de nomes foi significativamente maior do que o emprego de verbos até 1:08. Entre 02:06 e 03:03 essa diferença foi atenuada, mas persistiu. A inversão dessa tendência ocorreu em termos de ocorrência, como nos dados de SM. Embora tenha ocorrido de forma mais precoce do que na criança brasileira, verbos passaram, então, na produção de Pauline, a ser mais frequentes do que nomes a partir de 02:08. Nos dados de SM, essa inversão ocorre quando tem 2:11.

Abaixo, introduzimos dois gráficos contendo números absolutos dos dados representados na Figura 2. Na representação visual abaixo, é possível compreender melhor a progressão das duas categorias trabalhadas e identificar momentos de aceleração relativos ao desenvolvimento do léxico de verbos e nomes. 
Figura 3 - Frequências absolutas de tipos e ocorrências

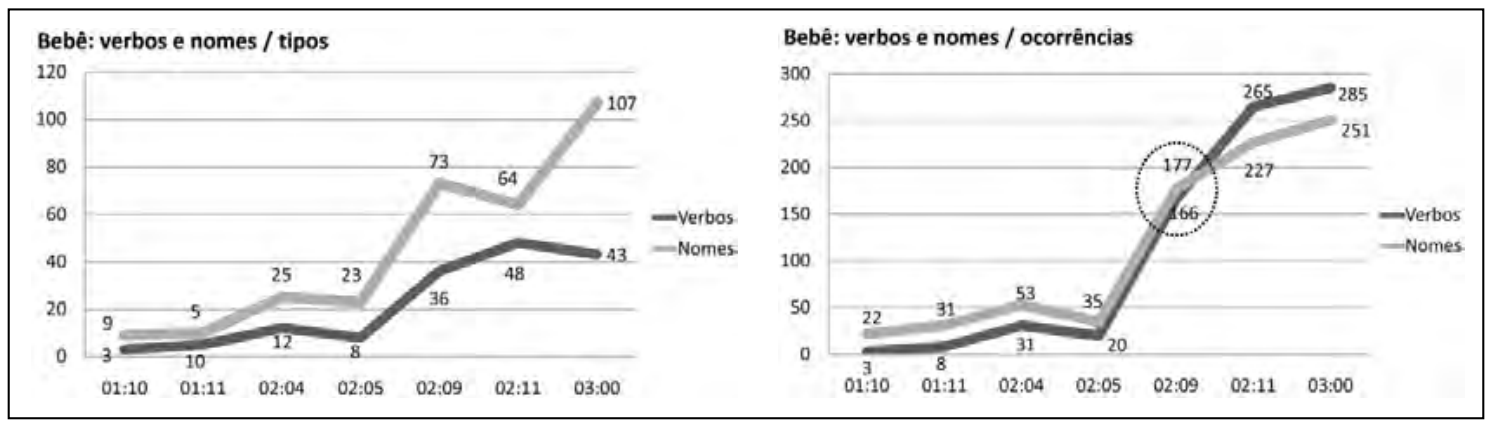

Nesses dois gráficos, verificamos uma evolução constante - tanto de verbos quanto de nomes - nas amostras de SM. A diferença quanto às figuras anteriores, que mostravam percentuais relativos às categorias estudadas, é a de que apresentam frequências absolutas, o que facilita a identificação de pequenas e grandes explosões lexicais tanto para tipos quanto para ocorrências.

Para a frequência de tipos, como relatado, nomes são predominantes. No gráfico da esquerda, verificamos essa predominância em todas as amostras, mas identificamos, também, que os nomes progridem de modo nitidamente ascendente. Três explosões podem ser destacadas: a primeira entre 01:11 e 02:04 (período em que o número de itens lexicais diferentes aumenta de 5 para 25), a segunda entre 02:05 e 02:09 (intervalo em que há aumento de 23 para 73 nomes diferentes) e a terceira entre 02:11 e 03:00 (quando há salto quantitativo de nomes de 64 para 107 itens). Em relação aos verbos, a grande explosão compreende o período que vai de 02:04 a 02:11.

Para a frequência de ocorrências, destacada no gráfico da direita, o desenvolvimento é mais lento nas quatro primeiras amostras, embora possamos identificar uma pequena explosão entre 01:11 e 02:04 para verbos. Depois de 02:05, a frequência total de verbos explode. 53 verbos, aproximadamente, são empregados em 02:04; 285 em 03:00. Ocorre algo similar em relação aos nomes, mas, na quinta amostra, o ritmo ascendente dos nomes diminui e o número de nomes e verbos fica próximo (177 verbos e 166 nomes). Na amostra seguinte, há inversão da tendência inicial, ou seja, os verbos tornam-se mais frequentes na produção do informante. 
Esses resultados apoiam o modelo "from reference to predication to grammar", proposto por Bates et al (1994).

\section{Emergência (desenvolvimento) dos tempos verbais (do sistema modo temporal)}

A Figura 4 é composta pelos tempos verbais empregados por SM nas sete amostras analisadas. Nenhuma forma composta faz parte desse conjunto. Porém, aquelas que poderiam compô-las como o infinitivo, o gerúndio e o particípio, por exemplo, não foram excluídas, pois serão utilizadas no cálculo do índice relativo à gramaticalização dos verbos dessas amostras. Observemos, abaixo, a distribuição e o desenvolvimento dessas formas nas sete coletas selecionadas neste estudo.

Figura 4 - Desenvolvimento do sistema modo temporal

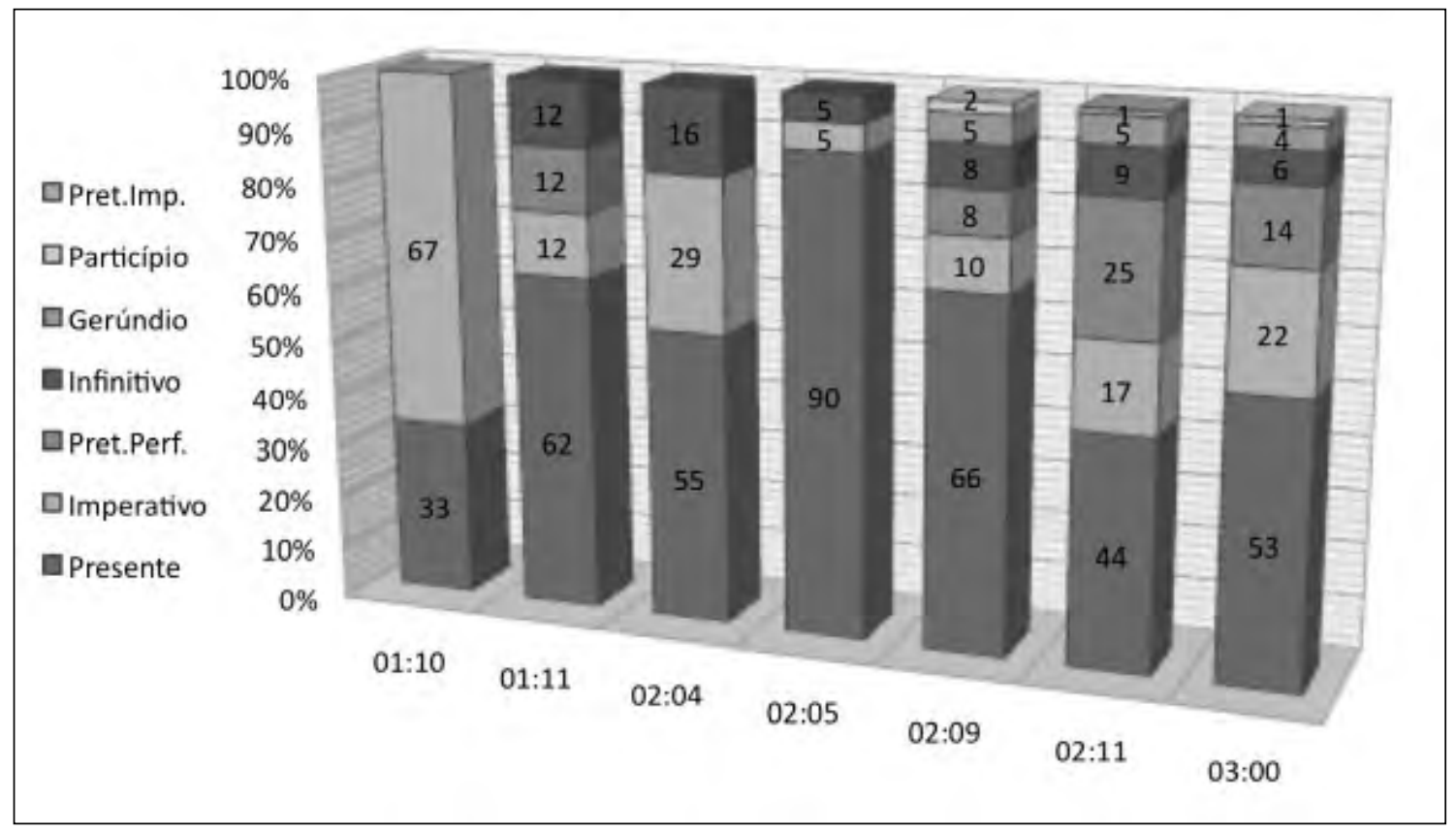

Quando as coletas de dados iniciaram (01:10), o informante já dispunha de alguns itens lexicais, podendo realizar enunciados compreendendo duas palavras. Na maior parte do tempo, SM as combinava acrescentando sílabas, com padrão $\mathrm{CV}$ próximas ao balbucio. A coexistência do balbucio e das 
primeiras palavras foi atestada em muitos dados empíricos (HALLÉ, 1998), podendo persistir até o final do segundo ano. SM produzia enunciados contendo poucos elementos relacionais, mas eles já estavam presentes na sua fala. Nessa primeira produção, empregou duas formas verbais distintas: o presente do indicativo (33\%) e o imperativo (67\%). A entrada de SM na linguagem, levando em consideração a temporalidade morfológica, parece ter ocorrido por meio dessa última forma. Pelo menos é o que aponta a alta freqüência do imperativo, quando comparada ao uso do presente do indicativo.

A emergência precoce do imperativo pode estar relacionada a um conjunto de comportamentos que, segundo Tomasello (2003) aparece entre nove e doze meses de idade. Trata-se de habilidades e interações sociais triádicas compostas pela criança, pelo adulto e por um objeto ou evento ao qual, ambos, dirigem a atenção. Nesse período, a criança começa a realizar gestos dêiticos - imperativos ou declarativos -, a fim de que "os adultos sintonizem com sua atenção para alguma entidade exterior" (p. 86). Com o advento da linguagem articulada, a criança potencializaria o que já fazia com o auxílio de gestos proximais (como o de mostrar) e distais (como os de apontar).

Na segunda amostra (01:11), o emprego do imperativo diminui consideravelmente (12\%) e o presente do indicativo instala-se na fala da criança (62\%). Com proporções idênticas as do imperativo, emergem o pretérito perfeito (12\%) e o infinitivo (12\%). Nesta etapa, esses percentuais equivalem a uma única ocorrência de cada uma dessas formas. O infinitivo será empregado em todas as coletas subseqüentes, mas o pretérito perfeito ressurgirá somente nas últimas três amostras. Ambos, infinitivo e pretérito perfeito, emergem sem atingir índices de produtividade nesse segundo momento.

Nas terceira e quarta amostras (02:04 e 02:05) são utilizados o presente do indicativo (55\% e $90 \%$, respectivamente), o imperativo ( $29 \%$ e $5 \%$ ) e o infinitivo ( $16 \%$ e $5 \%$ ). O presente do indicativo e o imperativo evoluem de modo muito diverso. O primeiro ascende, enquanto o segundo - desde a segunda amostra - deixa de ser o tempo verbal mais empregado.

As três últimas amostras (02:09, 02:11 e 03:00) continuam a ilustrar a predominância do presente do indicativo $(66 \%, 44 \%$ e 53\%), mas também o modo como se instala nesses dados: re- 
cua, embora atinja patamares elevados de uso (média de 53\% nessas últimas coletas). É, pois, o tempo verbal mais estável e hegemônico. O imperativo continua a ser utilizado ocupando o segundo lugar no escore dessa competição (10\%, 17\% e 22\%). Resultado similar atinge o pretérito perfeito na $3^{\text {a }}$ pessoa do singular $(8 \%, 25 \%$ e $14 \%)$, que desde a quinta amostra se torna produtivo. Há recorrência dessa forma, pois já havia sido empregada, de modo isolado, na segunda amostra. Ainda, na sexta amostra, tem lugar a única ocorrência do pretérito imperfeito (1\%). Trata-se, pois, de uma forma complexa cuja aquisição é tardia. Duas formas nominais surgem: o gerúndio (5\%, 5\% e $4 \%$ ) e o particípio ( $2 \%$ na sexta amostra e $1 \%$ na última). Junto com o infinitivo, elas têm um papel importante no processo de gramaticalização, como veremos no tópico 5.3. Antes disso; porém, descrevemos tendências desenvolvimentais de duas formas verbais - o presente e o pretérito perfeito do indicativo.

\section{Tendência desenvolvimental do presente do indicativo}

A Figura 5 contém o modo como o presente do indicativo é, aos poucos, adquirido por SM. Identificamos o modo como a criança adquire o conjunto de posições que determinam essa forma verbal, segundo a sua referência à pessoa.

Figura 5 - Evolução do presente do indicativo

\begin{tabular}{|c|c|c|c|c|c|c|c|}
\hline \multirow{2}{*}{\multicolumn{8}{|c|}{$\begin{array}{l}120 \\
100\end{array}$}} \\
\hline \multirow{2}{*}{\multicolumn{8}{|c|}{$\begin{array}{r}100 \\
80\end{array}$}} \\
\hline \multirow{2}{*}{\multicolumn{8}{|c|}{60}} \\
\hline & & & & & & & \\
\hline \multicolumn{8}{|l|}{40} \\
\hline \multicolumn{8}{|l|}{20} \\
\hline 0 & 01:10 & 01:11 & 02:04 & 02:05 & 02:09 & 02:11 & 03:00 \\
\hline - 3ps & 100 & 100 & 82 & 94 & 75 & 75 & 73 \\
\hline 1ps & & & 18 & 6 & 24 & 14 & 17 \\
\hline = 2ps & & & & & 1 & 8 & 3 \\
\hline -1pp & & & & & & 3 & 6 \\
\hline$=3 p p$ & & & & & & & 1 \\
\hline
\end{tabular}


Como é possível constatar, a $3^{a}$ pessoa do singular domina as duas primeiras amostras (01:10 e 01:11). Nessas coletas, a forma é empregada, exclusivamente, com o verbo ter. O emprego, existencial, ocorre nas construções do tipo ter + entidade (objeto). Na terceira amostra (02:04), o uso da $3^{\mathrm{a}}$ pessoa do singular (14 ocorrências) se estende a outros verbos (fazer, $i r$, ser, estar e comer), tornando-se produtiva. Fazer e ter são, nesta etapa, os verbos mais empregados pelo informante. $\mathrm{Na}$ quarta amostra (02:05), há aumento tímido da terceira pessoa do singular, tanto de ocorrências como de tipos. Com efeito, esta forma é produzida 17 vezes e somente mais um tipo é acrescido à lista anterior. $\mathrm{O}$ novo verbo disponível é tomar no sentido de beber. Na quinta amostra (02:09), o presente do indicativo na $3^{\text {a }}$ pessoa do singular explode, representa $50 \%$ do conjunto de formas empregadas pela criança, o que equivale a 83 ocorrências. $\mathrm{O}$ número de tipos, porém, não aumenta na mesma proporção: três somente e uma única ocorrência para cada um, a saber: conseguir, querer e saber. Os verbos ser, estar e ter são os mais presentes, representando mais de $90 \%$ das ocorrências dessa amostra. $\mathrm{O}$ aumento de ocorrências dessa categoria na sexta amostra (02:11) é pouco expressivo, mas o número de tipos torna-se quase duas vezes maior. As novas bases verbais empregadas são parar, dar, deitar, faltar e funcionar. Há, no entanto, poucas ocorrências dessas novas bases, isto é, duas de cada um dos primeiros dois verbos e uma de cada um dos quatro últimos citados. Enfim, na sétima amostra (03:00), identificamos 110 ocorrências do presente do indicativo na terceira pessoa do singular e o acréscimo de mais seis verbos diferentes (tipos) - andar, sair, abrir, parecer, subir e voar -, sendo que somente os dois primeiros são empregados mais de uma vez (duas e três vezes, respectivamente).

A primeira pessoa do singular emerge na terceira amostra (02:04). São três ocorrências e dois tipos (ser e querer) utilizados. Na quarta amostra (02:05), ela é empregada uma única vez. Trata-se de achar, expressando o ato de pensar, um verbo de cunho psicológico. Na quinta amostra (02:09), há uma explosão dessa forma em termos de ocorrências, pois ela é produzida 26 vezes. Os tipos aumentam (15 ocorrências do verbo saber, 8 de $i r$ e 1 de pegar), mas esse processo é lento. Na sexta amostra (02:11), as ocorrências diminuem (16) e apenas mais um tipo 
é empregado (andar), uma única vez. Na última amostra, as ocorrências aumentam em relação à amostra anterior, mas não em relação à quinta amostra. Identificamos 26 amostras e três novos tipos (ajudar, conseguir e montar). Somente uma ocorrência de cada um desses tipos foi produzida.

A $2^{a}$ pessoa do singular emerge na quinta amostra (02:09), com uma única ocorrência associada ao verbo deixar. Na sexta amostra (02:11), a forma torna-se produtiva: seis verbos são identificados - querer, cantar, estar, ficar, ligar e saber -, sendo que há cinco ocorrências do verbo querer. A ampliação do emprego das $3^{\mathrm{a}}$ e $1^{\mathrm{a}}$ pessoas a outras bases verbais ocorre de modo lento. Na última amostra, há somente 4 ocorrências do presente do indicativo e o uso de dois tipos distintos ir e montar (uma ocorrência de cada).

Enfim, nas últimas duas amostras emergem as $1^{\mathrm{a}}(02: 11)$ e $3^{\text {a }}(03: 00)$ pessoas do plural associadas ao verbo $i r$. Na sexta amostra, encontramos três ocorrências da $1^{\mathrm{a}}$ pessoa do plural. Na última, dez. A $3^{a}$ pessoa do plural, presente na última amostra, aparece uma única vez. Não há índice de produtividade em relação a essas duas pessoas do plural.

\section{Tendência desenvolvimental do pretérito perfeito do indicativo}

O pretérito perfeito é utilizado de forma isolada na segunda amostra (01:11). Identificamos uma única ocorrência com o verbo acabar na seguinte situação: mãe e filho conversam e ela deseja que ele cante uma música específica:

Mãe - Como é que é a música? Do gatinho? Como é que é aquela? Ti, tirim, tirim, tim (...)

$\mathrm{SM}$ - [akabo] tirim tirim (...)

Mãe: É, acabou.

SM - boi, boi, boi, boi da peta (...)

Acabar expressa, no sistema de SM, o desejo de cantar outra música (no caso, a do boi da cara preta) ou, dito de outro modo, uma maneira de negar algo que não deseja (a música do gatinho) ou, ainda, o de finalizar um assunto que não lhe agrade e redirecionar a atenção do adulto para a temática de 
seu interesse. Embora não possamos dizer, ainda, que SM adquiriu o pretérito perfeito, já que não temos, nessa etapa, um índice produtivo, mesmo que fraco, que permita essa conclusão; podemos propor o começo dessa aquisição pela criança, pois a forma é empregada de modo convencionalmente apropriado. Na quinta amostra (02:09), o pretérito perfeito na $3^{\mathrm{a}}$ pessoa do singular reaparece nos dados. $\mathrm{O}$ verbo andar faz parte dos tipos empregados, mas outros sete surgem (sumir, cair, aparecer, comprar, conseguir, ir e fazer). Das treze ocorrências contabilizadas, sete foram efetuadas com os verbos sumir e cair (4 e 3 ocorrências, respectivamente). Na sexta amostra (02:11), há explosão da $3^{\text {a }}$ pessoa do singular: são 42 ocorrências e 21 tipos. Cair, ao lado de chorar, são as bases verbais mais recorrentes: cinco de cada uma. Os outros tipos são faltar, morder, ser, funcionar, quebrar, sair, sentar, caber, cortar, dar, ficar, matar, parar, pegar, tirar e virar, além de ir, sumir e fazer, presentes na amostra anterior. Por fim, na sétima amostra (03:00), o pretérito simples na $3^{\mathrm{a}}$ pessoa do singular diminui em número de ocorrências (28) e tipos (18), mas dentre os utilizados, sete são novos (achar, arranhar, comer, contar, encontrar, fechar, levar e virar).

A primeira pessoa do singular do pretérito perfeito é empregada na sexta amostra (02:11). Compilamos 20 ocorrências realizadas com 9 verbos diferentes. Achar, colocar e pegar são as bases verbais mais empregadas (6, 5 e 3 ocorrências, respectivamente). Os verbos acertar, cair, conseguir, falar, quebrar e rasgar aparecem uma única vez.

A segunda pessoa do singular surge na sexta amostra (02:11). São apenas três ocorrências e dois tipos: achar e acertar. Na última amostra (03:00), SM emprega a segunda pessoa cinco vezes e utiliza três tipos: achar, montar e ver.

Da progressão descrita relativa ao desenvolvimento da categoria de pessoa do presente e do pretérito do indicativo, destacamos os seguintes aspectos: (i) tanto em tipos quanto em ocorrências, o uso da $3^{\text {a }}$ pessoa do singular é preponderante em todas as amostras, (ii) as pessoas do verbo associadas ao singular são precoces e as relativas ao plural tardam a emergir (iii) o aumento de bases verbais associadas a cada uma das categorias analisadas ocorre de modo lento e gradual. 
Figura 6 - Evolução do pretérito perfeito do indicativo

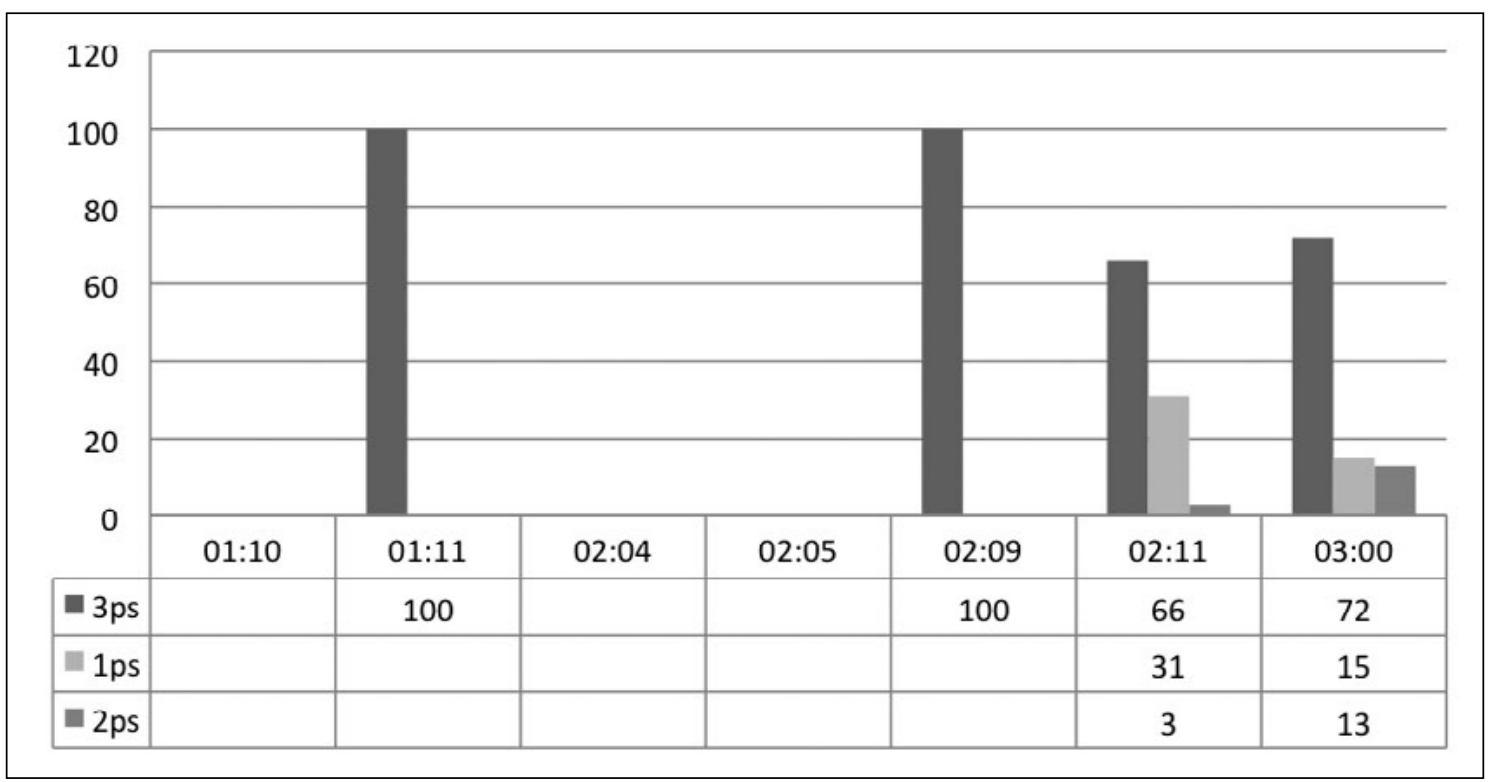

Bassano et al (2001) identificaram as seguintes progressões para as categorias de pessoa do verbo durante os três primeiros anos de Pauline e Katharina (criança austríaca): (i) em língua francesa, as $3^{\mathrm{a}}$ e $1^{\mathrm{a}}$ pessoas foram as mais precoces e frequentes (01:02 e 01:03, respectivamente); (ii) a $2^{\mathrm{a}}$ pessoa do singular foi tardia (01:07) em relação às anteriores; (iii) ainda, a $3^{a}$ pessoa do plural emergiu quando Pauline tinha 01:09, continuando pouco frequente mesmo quando atinge o critério de produtividade (02:05). Em alemão austríaco, (i) o presente do indicativo foi produzido nas três pessoas do singular e nas $1^{\text {a }}$ e $3^{\text {a }}$ pessoas do plural; (ii) a $1^{\text {a }}$ pessoa do singular foi produzida aos 02:00 e (iii) as $2^{\text {a }}$ e $3^{\text {a }}$ pessoas do singular aos 02:04; (iv) ainda mais tardias e pouco frequentes, a $1^{\mathrm{a}}$ pessoa do plural emergiu aos 02:06 e a $3^{\mathrm{a}}$ pessoa do plural, aos 02:10.

As evoluções de SM fora idênticas às da criança de língua alemã e, ambas, parecidas com as progressões da criança francesa. Tanto as diferenças de ritmo dessas aquisições, quanto as variações existentes entre esses desenvolvimentos, podem ser atribuídas às línguas maternas dos informantes e a aspectos 
individuais de cada criança. De qualquer modo, identificamos uma mesma ordem na apropriação desses três sistemas linguísticos: o movimento se realiza do singular em direção ao plural.

\section{Gramaticalização}

O índice de gramaticalização proposto compreende a relação existente entre o número de formas verbais compostas e o número de infinitivos, gerúndios e particípios utilizados. Dentre esses últimos, a forma infinitiva é a mais precoce, emerge na segunda amostra (01:11), mas o seu emprego é isolado não formando estruturas complexas.

A primeira forma composta surge na terceira amostra (02:04). Trata-se de duas ocorrências do futuro perifrástico composto de $i$, na $3^{a}$ pessoa do singular, e do verbo cair no infinitivo. Embora represente $16 \%$ das formas verbais empregadas por SM nessa amostra, seu emprego é limitado. Na quarta amostra, as formas compostas não se desenvolvem. A explosão dessas formas ocorre na quinta amostra, estágio em que diferentes verbos são empregados na forma infinitiva (14 ocorrências e 12 tipos), no gerúndio (9 ocorrências e sete tipos) e no particípio (4 ocorrências e três tipos).

As formas compostas mais recorrentes são formadas por ir e querer seguidos de verbo no infinitivo e estar seguido de gerúndio ou particípio. Ir seguido de infinitivo é a única dessas formas utilizada na $1^{\text {a }}$ pessoa do singular do presente do indicativo e na $3^{\text {a }}$ pessoa do singular do pretérito perfeito. Estar seguido de gerúndio ou particípio é quase exclusivamente empregado na $3^{\text {a }}$ pessoa do singular do presente do indicativo. Surgem três ocorrências da $1^{\mathrm{a}}$ pessoa do singular do presente do indicativo na última amostra, apenas. Querer seguido de infinitivo aparece em todas as três pessoas do singular. Essas combinações revelam (i) índices importantes de gramaticalização, presentes na quinta amostra $(0,85)$ e mantidos nas duas últimas coletas $(0,72$ e 0,87$)$, (ii) a dificuldade da criança em formar complexos verbais associados ao pretérito perfeito, (iii) o emprego massivo dessas formas na $3^{\text {a }}$ pessoa do singular do presente do indicativo, (iv) o emprego tardio das formas associadas ao plural. 
Figura 7 - Gramaticalização das formas complexas

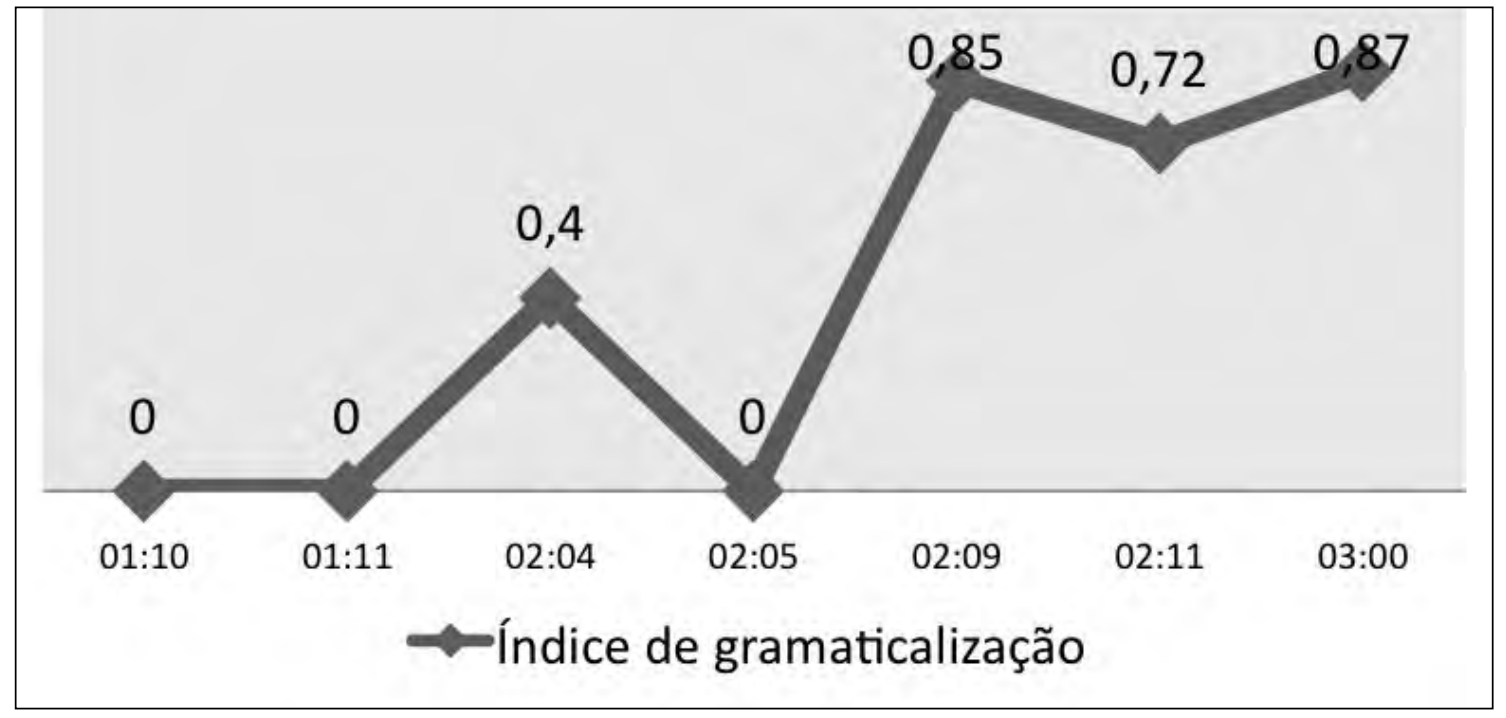

Nos resultados obtidos por Bassano (2005), Pauline não produz formas compostas, em francês, antes dos 23 meses. Esse tipo de construção atinge o nível de 0,80, taxa associada à explosão desse aspecto da gramaticalização dos verbos, aos 29 meses (02:05), ou seja, depois da explosão da produção lexical dessa categoria de palavras nos dados da criança francesa. Ainda, em pesquisa que visava a comparação do desenvolvimento da morfologia verbal em francês e em alemão (BASSANO et al, 2004), os resultados demonstraram que a explosão gramatical também ocorria depois da explosão lexical relativa aos verbos, o que indicaria uma dependência entre o desenvolvimento lexical e o desenvolvimento gramatical. Nos resultados obtidos nas análises dos dados de SM, A hipótese da "massa lexical crítica" tende a ser reforçada. De fato, há explosão de tipos, no que diz respeito aos verbos, entre 2:05 e 02:09 (Figura 3) e início da explosão da gramaticalização dessa categoria quando SM tem 02:09.

\section{Conclusão}

Neste trabalho, assumimos um enfoque emergentista a fim de traçar o caminho percorrido pela criança durante a conquista progressiva da linguagem articulada. Defendemos uma concepção integrativa da aquisição da linguagem, ou seja, 
a aquisição e o desenvolvimento da linguagem resultariam do produto de interações entre diferentes componentes da capacidade linguística - como fonologia e léxico; e morfologia e léxico, especificamente nesta pesquisa.

As descrições efetuadas acerca da emergência dos tempos verbais indicaram que o uso da fala para a realização de deslocamentos no tempo - em relação ao eu, aqui e agora -, por meio de uma forma conjugada do verbo, é tarefa árdua e lenta. O presente do indicativo instala-se muito precocemente, mas o pretérito perfeito tarda a ser adquirido. Klein (1989), comentando a aquisição da primeira língua, destaca o fato de as crianças pequenas ainda confundirem "ontem", e "amanhã", mesmo quando já têm quatro ou cinco anos de idade. Uma explicação para essa dificuldade remete à dupla tarefa a ser efetuada pela criança: a compreensão do conceito de tempo (presente e passado, por exemplo) e a aquisição das formas adequadas para marcá-lo gramaticalmente. Há, pois, uma dificuldade de cunho cognitivo para que as formas possam emergir e ser adequadamente utilizadas. Essa não é, porém, a única explicação para o lento curso da aquisição de certas formas.

O início da gramática infantil revela-se por meio da capacidade da criança em combinar palavras. Bates et al (1999) identificaram um período considerado ótimo para a sua manifestação: o seu começo ocorreria entre 20 e 36 meses. Esses pesquisadores destacaram que esse intervalo de tempo é "caracterizado por acontecimentos drásticos no desenvolvimento pós-natal do cérebro (...), o que significa que os fatores biológicos podem ter um papel particularmente importante nos aspectos da linguagem que mudam durante o mesmo período" (p.87). Essa é, também, uma etapa importante para o desenvolvimento de nossa espécie, pois boa parte da ontogênese humana ocorre durante a interação da criança com o ambiente. Segundo Tomasello (2003), a "vantagem que compensa a longa imaturidade é que isso abre vias ontogenéticas que incorporam quantidades significativas de aprendizagem e cognição individual, o que costuma resultar em adaptações comportamentais e cognitivas mais flexíveis" (p. 17-18). Essas observações levam a produtos variáveis resultantes de interações entre biologia e ambiente. Aspectos gerais do desenvolvimento podem, desse modo, estar associados, no caso 
do desenvolvimento linguístico, a predisposições inatas e ao impacto do entorno social da criança, igualmente.

Ainda, o trabalho apresentado e as pesquisas realizadas com crianças francesas e austríacas identificaram um fator de cunho "interno" responsável pelo desenvolvimento da linguagem. Assim, além da aquisição da linguagem sofrer o impacto de fatores genéticos e ambientais, ela também é sensível às interações internas ao sistema, isto é, às inter-relações dinâmicas que ocorrem entre o léxico e a gramática, no caso do presente estudo.

Outros fatores responsáveis pela evolução do sistema linguístico infantil podem ser melhor investigados: o impacto do input linguístico e a influência das propriedades léxico-semânticas do verbo no processo de gramaticalização, por exemplo. É, pois, nessa direção que orientamos as nossas investigações em trabalhos futuros.

\section{REFERÊNCIAS BIBLIOGRÁFICAS}

BATES, E.; DALE, P. S.; THAL, D. Diferenças individuais e suas implicações para as teorias do desenvolvimento da linguagem. In FLETCHER, P.; MACWHINNEY, B. Compêndio da linguagem da criança. Porto Alegre: Artes Médicas, 2007.

BATES, E. e GOODMAN, J.C. On the emergence of grammar from the lexicon.. In B. MacWhinney (Ed.), The emergence of language. New Jersey: Lawrence Erlbaum Associates, 1999.

BATES et al. Developmental and stylistic variation in the composition of early vocabulary. Journal of Child Language, 21, 1, 1994.

BASSANO et al. L'acquisition de la morphologie verbale en français et en allemand autrichien : II. L'épreuve des faits. Enfance, 2, 2001.

BASSANO, D. L'acquisition des verbes en français : un exemple de l'interface lexique/ grammaire. Synergies, nº 6, 2010.

. Développement du lexique et émergence de la grammaire. Le langage et l'homme, vol. XXXX, nº2. Bruxelas: E.M.E., 2005.

Lélaboration du lexique précoce chez l'enfant français : structure et variabilité. Enfance, 4, 1998

GENTNER, D. On relational meaning : the acquisition of verb meaning. Child Development, 1976. 
GLEITMAN, L. R. The structural sources of verb meaning. Language Acquisition, 1, 1990.

HALLÉ, P. A. Les productions vocales des jeunes enfants français : convergence vers le modèle adulte. Langue Française, 118. Paris : Larousse, 1998.

KLEIN, W. L'acquisition de langue étrangère. Paris : Armand Colin, 1989.

QUINTERO, Y.C. e PÉREZ, C. I. Proporción de sustantivos $\mathrm{y}$ verbos en el habla del cuidador y en el léxico temprano en español. Boletín de Linguística, vol. XIX, núm. 27, 2007.

SARDINHA, T. B. Usando WordSmith Tools na investigação da linguagem. DIRECTPapers, 1999.

TOMASELLO, M. Origens culturais da aquisição do conhecimento humano. São Paulo: Martins Fontes, 2003.

\section{Abstract \\ Lexical development and grammaticalization in the acquisition of Brazilian Portuguese}

This paper relies on a functionalist and an emergentist perspective of the language acquisition process, in which grammatical patterns are designed as structures that emerge from the lexicon. It aims at reflecting on how the acquisition of verbal lexicon and the grammaticalization phenomenon occur. The results support the model "from reference to predication to grammar" and the hypothesis of "critical mass" proposed by Bates et al $(1994,1997)$ and Bates and Goodman (1999).

Key words: verbal morphology; language acquisition; grammaticalization 